\title{
Material didático utilizado na Educação Profissional de Jovens e Adultos: Uma revisão sistemática da literatura
}

\section{Didactic material used in Professional Education for Young People and Adults: A systematic literature review}

\author{
SILVA, Gercivania Gomes da. Discente do Programa de Mestrado Profissional em \\ Educação Profissional e Tecnológica (ProfEPT). \\ Instituto Federal de Educação Ciência e Tecnologia do Sertão Pernambucano-IFSertãoPE - Campus Salgueiro. BR \\ 232, Km 08 - Salgueiro - Pernambuco - Brasil. CEP:56.000-000 / Telefone: (87) 99654-2322 / E- \\ mail:gercivania.gomes@ifsertao-pe.edu.br
}

\section{OLIVEIRA, Francisco Kelsen de. Doutor em Ciência da Computação}

Instituto Federal de Educação Ciência e Tecnologia do Sertão Pernambucano-IFSertãoPE - Campus Salgueiro. BR 232, Km 08 - Salgueiro - Pernambuco - Brasil. CEP:56.000-000 / Telefone: (85) 98817-8151 / E-

mail:francisco.oliveira@ifsertao-pe.edu.br

\section{RESUMO}

O Programa Nacional de Integração da Educação Profissional com a Educação Básica na Modalidade de Educação de Jovens e Adultos (PROEJA) atende jovens e adultos que não tiveram acesso ao sistema escolar na infância e na adolescência ou que, por qualquer motivo, tenham interrompido seus estudos. Este trabalho tem como finalidade ampliar os conhecimentos acerca da EJA bem como da educação profissional e do material didático utilizado nessa modalidade de ensino. Trata-se de uma Revisão Sistemática da Literatura feita a partir das publicações em bases de dados multidisciplinares com delimitação temporal de 2008 a 2021 no intuito de reunir materiais que permitissem a expansão dos conhecimentos em torno da temática. Foram encontrados 184 resultados nas bases listadas, dentre essas publicações, somente dez atendiam ao primeiro critério de inclusão. Após a leitura integral dos artigos, percebeu-se que quatro deles não tratavam realmente do tema de interesse e não atendiam ao segundo critério de inclusão. Os trabalhos selecionados foram publicados a partir do ano de 2011 e na grande maioria traziam observações voltadas à preocupação com a proposta curricular e com a formação docente. As publicações analisadas vêm a contribuir para as discussões acerca do PROEJA e dos recursos didáticos utilizados nas aulas nessa modalidade, pois evidenciam a importância da consolidação dos direitos desses brasileiros que não concluíram a educação básica, pensando a modalidade não como algo compensatório, mas como uma política que contribua com o fim do processo de exclusão desses sujeitos.

Palavras-chave: Educação profissional de Jovens e Adultos, material didático, Revisão Sistemática de Literatura

\section{ABSTRACT}

The Professional Education Integration National Program with Basic Education in the modality of Youth and Adult Education (PROEJA) serves young people and adults who have not had access to the school system in childhood and adolescence or who, for any reason, have interrupted their studies. This work aims to expand the knowledge about the PROEJA as well as the professional education and didactic material used in this type of teaching. This is a Systematic Literature Review made from publications in multidisciplinary databases with temporal delimitation from 2008 to 2021 in order to gather materials that would allow the expansion of knowledge around the theme. We found 184 results in the databases listed, among these publications, only ten met the first inclusion criterion. After full reading of the articles, it was noticed that four of them did not really address the theme of interest and did not meet the second inclusion criterion. The selected papers were published from 2011 and in the vast majority brought observations focused on the concern with the curricular proposal and with the teacher education. The analyzed publications contribute to the discussions about PROEJA and the didactic resources used in the classes in this modality, because they highlight the importance of consolidating the rights of these Brazilians who did not complete basic education, thinking of the modality not as compensatory, but as a policy that contributes to the end of the process of exclusion of these people.

Keywords: Professional Education for Youth and Adults, teaching material, Systematic Literature Review 


\section{Introdução}

O Programa Nacional de Integração da Educação Profissional com a Educação Básica na Modalidade de Educação de Jovens e Adultos (PROEJA) é um programa que integra educação básica e educação profissional, considerando que esta última é parte da educação integral do ser humano. Por isso, entende-se que os recursos didáticos devam ser voltados para o curso ofertado e, tendo um público diferente, a produção dos materiais didáticos precisa ser comprometida com essas diferenças, com o desenvolvimento do homem como um ser integral que se constitui a partir de sua relação com a natureza e com o trabalho, compreendendo o conhecimento como um direito de toda pessoa e que isso não pode se dar externamente às relações sociais que a constituem.

Percebe-se que os estudantes da Educação de Jovens e Adultos (EJA) têm um perfil diferente dos demais estudantes do ensino regular, pois são, na grande maioria, da classe proletária, donas de casa, jovens, desempregados, pessoas que não foram atendidas pelo sistema escolar na idade obrigatória ou que precisaram interromper os estudos por algum motivo, seja econômico, familiar, falta de interesse na aprendizagem, falta de estímulo, entre outros diversos fatores, portanto, possuem aspirações também distintas das aspirações das crianças e adolescentes que cursam o ensino dito regular, pois sendo o público da EJA composto basicamente de pessoas da classe trabalhadora, salvo raras exceções, esses alunos passam o dia em seus labores e à noite buscam recuperar o que lhes foi negado na idade certa, almejando elevar os seus níveis de conhecimento e também alcançarem melhores lugares no mercado de trabalho. Por isso, é fundamental conhecer quais recursos didáticos são utilizados nas aulas com esses alunos de perfis tão distintos, se os profissionais que organizam esse material levam em consideração a realidade dos estudantes ou, simplesmente, replicam o que é usado no curso na modalidade regular.

Nas concepções do PROEJA existentes no Documento-base (BRASIL, 2007, p.35) diz que o programa deve ter a capacidade de proporcionar educação básica sólida, em vínculo estreito com a formação profissional, ou seja, a formação integral do educando. Por isso, o professor da EJA não pode desconsiderar as necessidades de aprendizagem do aluno, posto que este já possui experiências pessoais e profissionais que devem ser levadas em conta pelos profissionais que atuam nesta modalidade.

Diante disso, questiona-se sobre quais materiais didáticos são destinados aos cursos do PROEJA, visto que muitas vezes são os mesmos utilizados no Ensino Médio Integrado ou até em cursos superiores. Há de se analisar os materiais utilizados no curso, tanto das disciplinas do núcleo comum como também das disciplinas técnicas. Será que os profissionais têm o cuidado de levar em conta as especificidades dos alunos antes de proporem os recursos didáticos que usarão nas aulas? E os alunos, que avaliação fazem desses materiais? Consideram serem ideais ou vislumbram uma modificação significativa na escolha?

Dessa forma, este trabalho visou compreender as diretrizes, o processo de seleção dos materiais didáticos, os exemplos de recursos educacionais e as práticas educacionais voltadas para o curso técnico em Edificações na modalidade de Educação Profissional de Jovens e Adultos por meio da técnica de Revisão Sistemática da Literatura. Isso posto, apresentaremos os materiais e métodos utilizados nesta pesquisa, os resultados obtidos e as conclusões a que chegamos. 


\section{Metodologia}

Visto que o presente trabalho tem como finalidade ampliar os conhecimentos acerca da educação de jovens e adultos bem como da educação profissional e do material didático utilizado nessa modalidade de ensino, trata-se de uma busca eletrônica para o levantamento das publicações em bases de dados multidisciplinares no intuito de reunir materiais que permitissem a expansão dos conhecimentos em torno da temática. As bases de dados utilizados foram: Google Acadêmico, Portal de Periódicos da Capes e Portal Scielo com delimitação temporal de 2008 a 2021. O recorte temporal deve-se ao fato de no ano de 2008 ter sido o ano de criação dos Institutos Federais de Educação, Ciência e Tecnologia no país.

Os termos utilizados nas buscas e a ordem a que seguimos estão discriminados no quadro a seguir:

Quadro 1: Termos selecionados para string de busca

\begin{tabular}{|l|l|l|l|}
\hline Termos de $1^{\text {a }}$ ordem & Termos de $2^{\mathrm{a}}$ ordem & $\begin{array}{l}\text { Termos de } \\
3^{\mathrm{a}} \text { ordem }\end{array}$ & $\begin{array}{l}\text { Termos de } 4^{\mathrm{a}} \\
\text { ordem }\end{array}$ \\
\hline $\begin{array}{l}\text { PROEJA; Educação de Jovens e } \\
\text { Adultos; Educação Profissional } \\
\text { de Jovens e Adultos }\end{array}$ & $\begin{array}{l}\text { Material didático; material } \\
\text { pedagógico; recursos } \\
\text { didáticos;recursos pedagógicos }\end{array}$ & $\begin{array}{l}\text { disciplinas } \\
\text { técnicas }\end{array}$ & Edificações \\
\hline
\end{tabular}

Fonte: Adaptado de Oliveira e Gomes (2015)

Para esta Revisão, foram considerados somente artigos completos ou resumidos publicados em anais de eventos e periódicos científicos nas bases listadas. A escolha por este filtro justifica-se por serem publicações geradas mais rapidamente, trazendo mais dinamicidade às pesquisas e atualizações das publicações sobre o assunto. Justifica-se, também, por serem trabalhos avaliados por bancas de profissionais da área. Estabelecer esses filtros foi fundamental para a confiabilidade nos trabalhos analisados, visto que a "literatura cinzenta" se faz cada vez mais acessível, principalmente pela internet e, por não terem um controle bibliográfico mínimo, não podem ser considerados em uma RSL que precisa respeitar o rigor metodológico que o trabalho exige.

A revisão limitou-se a estudos que tivessem incidência sobre a questão específica de pesquisa. No quadro a seguir, apresenta-se os critérios de inclusão e exclusão dos materiais a serem considerados para análise deste trabalho.

\section{Quadro 2: Critérios de inclusão e exclusão de materiais}

\begin{tabular}{|c|c|c|}
\hline Critérios & ID & Descrição \\
\hline Inclusão & I1 & $\begin{array}{r}\text { Artigos completos ou resumidos publicados em anais de eventos ou periódicos } \\
\text { científicos no acervo das bases listadas }\end{array}$ \\
\hline
\end{tabular}




\begin{tabular}{|c|c|c|}
\hline & 12 & Estudos desenvolvidos no âmbito da Educação Profissional de Jovens e Adultos \\
\hline \multirow{4}{*}{ Exclusão } & E1 & Trabalhos escritos em língua estrangeira \\
\hline & E2 & $\begin{array}{l}\text { Apresentação de slides ou resumos publicados em anais de eventos, artigos } \\
\text { publicados em magazine ou documentos oficiais regulatórios }\end{array}$ \\
\hline & E3 & $\begin{array}{c}\text { Trabalhos desenvolvidos que não contemplem a modalidade EJA ou a } \\
\text { contemple dissociada da Educação Profissional }\end{array}$ \\
\hline & E4 & $\begin{array}{c}\text { Trabalhos em plataformas com restrições de acesso a usuários ou que não } \\
\text { estejam disponíveis de forma gratuita }\end{array}$ \\
\hline
\end{tabular}

Fonte: Adaptado de Oliveira e Gomes (2015)

Os documentos que não atenderam aos critérios de inclusão já especificados não foram analisados, porém, foram deixados em uma pasta específica para eles com a especificação do motivo da exclusão desses. Isso, apesar de parecer custoso, poderá nos ajudar em um futuro controle do processo de revisão ou quando da explicitação da execução da metodologia, nos proporcionará a replicabilidade do estudo e permitirá que retrocedamos e reavaliemos os critérios de inclusão e protocolo em qualquer ponto durante a continuidade da revisão, além de estabelecer a confiabilidade do trabalho.

Para seguirmos uma linha de análise dos artigos selecionados, elencamos, no quadro que segue, as questões que a pesquisa visou levantar e as respectivas motivações.

Quadro 3: Perguntas da pesquisa e suas respectivas motivações

\begin{tabular}{|l|l|l|}
\hline ID & \multicolumn{1}{|c|}{ Questões da pesquisa } & \multicolumn{1}{|c|}{ Motivações } \\
\hline P1 & $\begin{array}{l}\text { Como está o estado da arte sobre recursos } \\
\text { didáticos para a Educação Profissional de } \\
\text { Jovens e Adultos? }\end{array}$ & $\begin{array}{l}\text { Conhecer a atual situação desse campo em } \\
\text { pesquisas e projetos acadêmicos }\end{array}$ \\
\hline P2 & $\begin{array}{l}\text { Que avaliação os alunos do PROEJA fazem do } \\
\text { material didático utilizado no curso? }\end{array}$ & $\begin{array}{l}\text { Entender como os estudantes avaliam o } \\
\text { material didático que lhes é apresentado } \\
\text { no decorrer do curso. }\end{array}$ \\
\hline P3 & $\begin{array}{l}\text { Os recursos didáticos utilizados no PROEJA } \\
\text { são especificamente elaborados para a } \\
\text { modalidade? }\end{array}$ & $\begin{array}{l}\text { Compreender como é o processo de escolha } \\
\text { dos recursos didáticos para a Educação } \\
\text { Profissional de Jovens e Adultos }\end{array}$ \\
\hline P4 & $\begin{array}{l}\text { Existe material didático específico para as } \\
\text { disciplinas técnicas do curso de edificações? }\end{array}$ & $\begin{array}{l}\text { Constatar se existe material didático } \\
\text { específico para as disciplinas técnicas do } \\
\text { curso de edificações }\end{array}$ \\
\hline P5 & $\begin{array}{l}\text { Quais as dificuldades encontradas pelos } \\
\text { professores com relação ao uso do material } \\
\text { didático disponível para o PROEJA? }\end{array}$ & $\begin{array}{l}\text { Identificar as possíveis barreiras no } \\
\text { processo de escolha de material didático } \\
\text { para o PROEJA }\end{array}$ \\
\hline
\end{tabular}

Fonte: Adaptado de Oliveira e Gomes (2015) 
Com base no protocolo de RSL (Revisão Sistemática de Literatura) estabelecido pelos autores e nos critérios de inclusão e exclusão já expostos no Quadro 2, na primeira etapa da pesquisa foi realizada a leitura dos resumos, das palavras-chave e das considerações finais dos artigos e na segunda etapa, a leitura do artigo completo das publicações que apresentavam as principais fundamentações teóricas e resultados que atendessem aos objetivos desta pesquisa. Na próxima seção, serão apresentados os resultados encontrados e as discussões desses, bem como suas contribuições para a temática em estudo.

\section{Resultados e discussão}

Foram encontrados 184 resultados no Google Acadêmico, um artigo no Portal de Periódicos da Capes e o Portal Scielo não apresentou nenhum resultado para os descritores escolhidos. Abaixo especificamos os tipos de trabalhos encontrados:

\section{Quadro 5. Resultados das buscas}

\begin{tabular}{|l|l|}
\hline Artigos em periódicos & 6 \\
\hline $\begin{array}{l}\text { Trabalhos publicados em anais de } \\
\text { eventos }\end{array}$ & 4 \\
\hline Teses de doutorado & 20 \\
\hline Monografia de graduação & 2 \\
\hline Documentos institucionais & 15 \\
\hline Monografia de especialização & 1 \\
\hline Dissertação de mestrado & 115 \\
\hline Ebooks & 5 \\
\hline Produtos educacionais & 1 \\
\hline Link corrompido & 16 \\
\hline \multicolumn{2}{|c|}{ Fonte: Próprios autores }
\end{tabular}

Dentre esses resultados, somente dez atendiam ao primeiro critério de inclusão (artigos completos ou resumidos publicados em anais de eventos ou periódicos científicos nas bases listadas), portanto, foram excluídos documentos institucionais ou regulatórios, monografias, teses, dissertações, ebooks e produtos educacionais, bem como trabalhos que apresentavam o link corrompido ou necessitavam de uma chave para acessá-los. Os dez trabalhos selecionados foram lidos integralmente e apresentaram como objetivo principal reflexões acerca da Educação Profissional técnica e tecnológica. Esses artigos serão descritos a seguir a partir de seus objetivos, métodos e resultados e as contribuições que trouxeram para as discussões em torno da Educação Profissional de Jovens e Adultos, bem como, do material didático utilizado nessa modalidade.

\section{Quadro 6. Análise dos trabalhos selecionados}

\begin{tabular}{|l|l|l|l|l|}
\hline Autor & $\begin{array}{l}\text { Técnicas utilizadas para } \\
\text { coleta de dados }\end{array}$ & $\begin{array}{l}\text { Contribui de } \\
\text { forma relevante à } \\
\text { EJA }\end{array}$ & $\begin{array}{l}\text { Apresenta } \\
\text { contribuição } \\
\text { significativa aos } \\
\text { estudos sobre } \\
\text { material didático }\end{array}$ & $\begin{array}{l}\text { Apresenta alguma } \\
\text { proposição }\end{array}$ \\
\hline $\begin{array}{l}\text { Silva et al } \\
(2021)\end{array}$ & Análise documental & & & \\
\hline $\begin{array}{l}\text { Silva e Cruz } \\
(2020)\end{array}$ & $\begin{array}{l}\text { Levantamento } \\
\text { bibliográfico }\end{array}$ & & & \\
\hline
\end{tabular}




\begin{tabular}{|c|c|c|c|c|}
\hline $\begin{array}{l}\text { Vale et al } \\
(2020)\end{array}$ & $\begin{array}{l}\text { Análise documental; } \\
\text { levantamento } \\
\text { bibliográfico }\end{array}$ & & & \\
\hline $\begin{array}{l}\text { Cavalcante } \\
\text { (2019) }\end{array}$ & $\begin{array}{l}\text { Análise documental; } \\
\text { levantamento } \\
\text { bibliográfico }\end{array}$ & $\checkmark$ & $\checkmark$ & 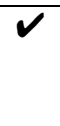 \\
\hline $\begin{array}{l}\text { Macêdo e } \\
\text { Kalhil (2017) }\end{array}$ & $\begin{array}{l}\text { Análise documental, } \\
\text { levantamento } \\
\text { bibliográfico; aplicação } \\
\text { de questionários }\end{array}$ & & & \\
\hline $\begin{array}{l}\text { Silva e Sá } \\
\text { (2016) }\end{array}$ & $\begin{array}{l}\text { Análise documental; } \\
\text { aplicação de } \\
\text { questionários e } \\
\text { entrevistas }\end{array}$ & $\checkmark$ & $\checkmark$ & \\
\hline $\begin{array}{l}\text { Miranda et } \\
\text { al (2015) }\end{array}$ & $\begin{array}{l}\text { Análise documental; } \\
\text { aplicação de } \\
\text { questionários }\end{array}$ & $\checkmark$ & & \\
\hline $\begin{array}{l}\text { Silva e Diniz } \\
\text { (2015) }\end{array}$ & $\begin{array}{l}\text { Análise documental; } \\
\text { aplicação de } \\
\text { questionários e } \\
\text { entrevistas }\end{array}$ & $\checkmark$ & $\checkmark$ & \\
\hline $\begin{array}{l}\text { Freitas e } \\
\text { Amaral } \\
(2012)\end{array}$ & Pesquisa-participante & $\checkmark$ & $\checkmark$ & $V$ \\
\hline $\begin{array}{l}\text { Boscaglia e } \\
\text { Sad (2011) }\end{array}$ & $\begin{array}{l}\text { Análise documental; } \\
\text { Observação; aplicação } \\
\text { de questionários }\end{array}$ & $\checkmark$ & 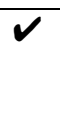 & \\
\hline
\end{tabular}

Fonte: Próprios autores

Os trabalhos selecionados foram publicados a partir do ano de 2011 e na grande maioria (80\%) traziam observações voltadas à preocupação com a proposta curricular e com a formação docente. Após a leitura integral dos artigos, percebeuse que quatro deles não tratavam realmente do tema de interesse e não atendiam ao critério de inclusão (estudos desenvolvidos no âmbito da Educação Profissional de Jovens e Adultos), sendo, portanto, excluídos do estudo.

técnicas utilizadas nos artigos para a coleta de dados foram: análises documentais, questionários, entrevistas, observações e levantamento bibliográfico. Quanto às temáticas abordadas, um artigo, Miranda et al (2015), contemplou a Educação Ambiental no âmbito do PROEJA; uma publicação, Boscaglia e Sad (2011), versou sobre o papel da geografia no currículo da EJA; duas publicações, Silva e Diniz (2015) e Silva e Sá (2016), apresentaram estudos sobre as propostas curriculares dos cursos; um abordou a disciplina de História como componente curricular na EJA, Cavalcante (2019) e um, Freitas e Amaral (2012), abordou as práticas que justificam os resultados positivos nas turmas de EJA.

Quanto à menção do material didático nos artigos, temos: dois trabalhos que afirmam serem inadequados os materiais didáticos utilizados no PROEJA e ressaltam serem os mesmos utilizados para os adolescentes, um artigo afirma que a disponibilização do material didático para os alunos pode diminuir os índices de evasão, um menciona sobre a importância do livro didático nas aulas e somente um artigo trata da relevância da participação do professor na elaboração do material didático que melhor atenda às necessidades do PROEJA. Nenhum dos trabalhos trouxe a visão do aluno ou do professor a respeito do material didático utilizado nas aulas.

Na publicação de Miranda et al (2015) indica-se a necessidade de atualização 
das políticas de forma a contemplar uma concepção sistêmica e articulada de meio ambiente que contemple aspectos humanos e naturais que contribuam para a formação de jovens e adultos participantes e ativos de um ambiente do qual ele faz parte juntamente com demais seres e processos vivos.

Boscaglia e Sad (2011) identificam que existem caminhos abertos para se constituir práticas de ensino integradas, envolvendo as disciplinas de formação geral e técnica, porém Silva e Diniz (2015) apontam que, talvez, essa realidade ainda esteja distante, pois seus estudos apontam um Ensino Médio Integrado com uma formação ainda desconectada de um currículo integrado.

Cavalcante (2019) aponta que o ensino na EJA deve contemplar a regionalidade e partir da exploração das experiências que os alunos trazem para dentro da sala de aula.

Os estudos de Freitas e Amaral (2012) apresentam proposições para resultados positivos nas turmas da EJA como a garantia da assistência estudantil e de infraestrutura adequada às atividades pedagógicas, a pouca rotatividade dos professores nas turmas e a construção de uma integração efetiva entre educação geral e educação profissional, visando um maior significado do que está sendo trabalhado com os alunos, a articulação entre teoria e prática, o recorte de conteúdos significativos para a formação proposta e para as próprias relações cotidianas da vida em sociedade.

\section{Considerações finais}

As publicações analisadas vêm a contribuir para as discussões acerca do PROEJA e dos recursos didáticos e pedagógicos utilizados nas aulas nessa modalidade, pois evidenciam a importância da consolidação e efetivação dos direitos desses brasileiros que não concluíram a educação básica, pensando a modalidade não como algo compensatório, mas como uma política que venha contribuir com o fim do processo de exclusão desses sujeitos, considerando-os em todas as dimensões e que fomente uma educação omnilateral pautada na autonomia e na emancipação para o exercício da profissão e da atuação política, social e cultural.

Os estudos que abordam o tema da Educação Profissional de Jovens e Adultos, de um modo geral indicam a necessidade de se constituir práticas de ensino integradas, articulando saberes fundamentados na indissociabilidade do trabalho e da cultura, além de materiais didáticos adequados ao público jovem e adulto, porém essa realidade ainda não se faz verdade, pois algumas instituições ainda estão a perseguir uma formação desconectada de um currículo integrado, fazendo mais do mesmo.

Identificou-se que nenhum dos trabalhos selecionados trouxe a preocupação em conhecer a avaliação que os alunos e os docentes da Educação de Jovens e Adultos fazem do material didático utilizado em sala de aula. Também não houve trabalho que discorresse sobre os aspectos conceituais e metodológicos desses materiais e nem sobre as diretrizes para a produção e/ou escolha desses. As leituras dos artigos selecionados também não nos permitiu identificar se existem materiais didáticos específicos para o curso de edificações na modalidade de Educação Profissional de Jovens e Adultos, porém, as discussões presentes nos artigos estudados contribuem para estimular o desenvolvimento de estratégias de estudos propositivos direcionados ao uso adequado de recursos didáticos que 
considerem as especificidades e experiências dos alunos da EJA.

\section{Referências}

BOSCAGLIA, Fabiano; SAD Ligia. Estudo sobre a geografia nos cursos técnicos do PROEJA / IFES Vitória - ES. Debates em Educação Científica e Tecnológica (Eletrônica), $\quad$ v. 1, p. 43-50, 2011. Disponível em: https://ojs2.ifes.edu.br/index.php/dect/article/view/6. Acesso em: 9 nov. 2021.

BRASIL. Ministério da Educação. Secretaria de Educação Profissional e Tecnológica. Educação Profissional Técnica de Nível Médio Integrada ao Ensino Médio. Documento Base. Brasília, 2007.

CAVALCANTE, Dehon da Silva. Ensino de história: autonomia, metodologias e reflexões curriculares na educação básica. In: II SEMINÁRIO NACIONAL DE ENSINO DE HISTÓRIA: DEMOCRACIA, LIBERDADE E AUTONOMIA, 2., 2019, Maceió. Anais eletrônicos do II Seminário Nacional de Ensino de História, Maceió: UFAL, 2019. p. 125-136.

Disponível em: http://www.ufal.edu.br/unidadeacademica/ichca/pesquisa/grupos/historia/centr o-de-pesquisa-e-documentacao-historicacpdhis/AnaisdollSeminrioNacionaldeEnsinodeHistriadaUFALCadernodeResumoseProg ramao.pdf. Acesso em: 9 nov. 2021.

FLICK, Uwe. Introdução à metodologia de pesquisa: um guia para iniciantes. Porto Alegre: Penso, 2013.

FREITAS, Aline Campelo Blank; AMARAL, Gisela Lange do. Curso Técnico em Execução, Conservação e restauro de Edificações - PROEJA: da concepção à prática. In: I SEMINÁRIO INTERNACIONAL E I FÓRUM DE EDUCAÇÃO DO CAMPO DA REGIÃO SUL: CAMPO E CIDADE EM BUSCA DE CAMINHOS COMUNS, 1., 2012, Pelotas. Anais eletrônicos do I seminário internacional e I fórum de educação do campo da região Sul, Pelotas: Ed. UFPel, 2012. p. 1-16. Disponível em: http://coral.ufsm.br/sifedocregional/images/Anais/Eixo\%2005/Aline\%20Campelo\%2 OBlank\%20Freitas.pdf. Acesso em: 9 nov. 2021.

MARCONI, Maria de Andrade; LAKATOS, Eva Maria. Fundamentos de metodologia científica. 8.ed. São Paulo: Atlas, 2017.

OKOLI, Chitu. Guia para realizar uma revisão sistemática da literatura. Tradução de David Wesley Amado Duarte; Revisão técnica e introdução de João Mattar. EaD em Foco, 2019;9 (1): e748. DOI: https://doi.org/10.18264/eadf.v9i1.748

OLIVEIRA, Francisco Kelsen de; GOMES, Alex Sandro. Uma revisão sistemática da literatura sobre ferramentas de autoria de IMS-LD. In: Anais do XXVI Simpósio Brasileiro de Informática na Educação (SIBE 2015). 2015

MACÊDO, Francisco Cristiano da Silva; KALHIL, Josefina Diosdada Barrera. Didática para desenvolver Habilidades Profissionais no Processo de Ensino e Aprendizagem da Física na Formação de Técnicos em Eletroeletrônica. LATIN - American Journal 
Of Physics Education. Cuba, v.11, p. 4301-1-4301-15, 2017. Disponível em: http://www.lajpe.org/ Acesso em: 9 nov. 2021.

MIRANDA, Bruno Britto de; PROFICE, Christiana Cabicieri; GUZMAN, Socrates Jacobo Moquete. A aplicação da política nacional de Educação Ambiental na modalidade de educação de jovens e adultos do IFBA. Revista Brasileira De Educação Ambiental (RevBEA), [S. l.], v. 10, n. 1, p. 257-280, 2015. DOI: 10.34024/revbea.2015.v10.1936. Disponível

em: https://periodicos.unifesp.br/index.php/revbea/article/view/1936. Acesso em: 9 nov. 2021.

SILVA, Bianca Reis da; CRUZ, Shirleide Pereira da Silva. Estudo bibliográfico sobre a licenciatura em educação profissional e tecnológica: questões para a profissionalidade docente. In: VIII SIMPÓSIO INTERNACIONAL TRABALHO, RELAÇÕES DE TRABALHO, EDUCAÇÃO E IDENTIDADE. 8., 2020, Belo Horizonte. Anais eletrônicos do VIII Simpósio Internacional Trabalho, Relações de Trabalho, Educação e Identidade. Belo Horizonte: CEFET-MG, 2020. p. 2-16. Disponível em: https://sitre.appos.org.br/wp-content/uploads/2021/01/GT-27-\%E2\%80\%93-

Formacao-de-professores-para-a-educacao-profissional.pdf. Acesso em: 9 nov. 2021.

SILVA, José Moisés Nunes da; DINIZ, Ana Lucia Pascoal. EMI no PROEJA no IFRN: Nova formação ou mais do mesmo? In: $37^{a}$ REUNIÃO NACIONAL DA ASSOCIAÇÃO NACIONAL DE PÓS-GRADUAÇÃO E PESQUISA EM EDUCAÇÃO - PLANO NACIONAL DE EDUCAÇÃO: TENSÕES E PERSPECTIVAS PARA A EDUCAÇÃO PÚBLICA BRASILEIRA. 37., 2015, Florianópolis. Anais eletrônicos da $37^{\text {a }}$ Reunião Nacional da ANPEd, Florianópolis: UFSC, 2015. p. 1-17. Disponível em: https://anped.org.br/sites/default/files/trabalho-gt18-4515.pdf. Acesso em: 9 nov. 2021.

SILVA, José Moisés Nunes da; SÁ, Lanuzia Tércia. O PROEJA no IFRN-campus Mossoró por seus estudantes. Holos (Natal Online), v. 7, p. 378-387, 2016. Disponível em: https://www2.ifrn.edu.br/ojs/index.php/HOLOS/article/view/4711. Acesso em: 9 nov. 2021.

VALE, Monnike Yasmin Rodrigues do; SILVA, Augusto Barbosa; PIMENTA, Jussara Santos. Estudo da formação de engenheiros ingressantes na carreira docente nos Institutos Federais do Brasil. Revista Brasileira da Educação Profissional e Tecnológica, $\quad$ v 2 2, p. 1-10, 2020. Disponível em: https://www2.ifrn.edu.br/ojs/index.php/RBEPT/article/view/11635/pdf. Acesso em: 9 nov. 2021.

VILARONGA, Carla Ariela Rios, et al. Inclusão escolar e atuação dos Núcleos de Apoio às Pessoas com Necessidades Educacionais Específicas no Instituto Federal de São Paulo. Revista Brasileira de Estudos Pedagógicos RBEP-INEP, v. 102, p. 283307, 2021. Disponível em: https://www.scielo.br/j/rbeped/a/CZy8XDFbQgzrYRjmqsgY8bJ/?format=pdf\&lang= pt. Acesso em: 9 nov. 2021. 